\title{
Sphingobium faniae sp. nov., a pyrethroid- degrading bacterium isolated from activated sludge treating wastewater from pyrethroid manufacture
}

Correspondence
Jian He
hejian@njau.edu.cn

\author{
Peng Guo, Bao-Zhan Wang, Bao-Jian Hang, Lian Li, Shun-Peng Li \\ and Jian $\mathrm{He}$
}

Key Laboratory of Microbiological Engineering of Agricultural Environment, Ministry of Agriculture, Life Sciences College of Nanjing Agricultural University, Nanjing, Jiangsu 210095, PR China

\begin{abstract}
A bacterial strain capable of degrading pyrethroid, designated $\mathrm{JZ}-2^{\top}$, was isolated from activated sludge treating pyrethroid-contaminated wastewater. Phylogenetic analysis based on 16S rRNA gene sequences indicated that strain $\mathrm{JZ}-2^{\top}$ belongs to the genus Sphingobium. It showed the highest levels of $16 \mathrm{~S}$ rRNA gene sequence similarity to Sphingobium cloacae JCM $10874^{\top}$ $(98.3 \%)$ and Sphingobium ummariense CCM $7431^{\top}(97.1 \%)$, and $94.8-96.9 \%$ similarity to the type strains of other members of the genus Sphingobium. Strain $\mathrm{JZ}-2^{\top}$ contained $\mathrm{C}_{18: 1} \omega 7 \mathrm{c}$ as the predominant fatty acid, $\mathrm{C}_{14: 0} 2-\mathrm{OH}$ as the major 2-hydroxy fatty acid, ubiquinone $\mathrm{Q}-10$ as the main respiratory quinone, diphosphatidylglycerol, phosphatidylglycerol, phosphatidylcholine, phosphatidylmonomethylethanolamine, phosphatidylethanolamine and two sphingoglycolipids as the predominant polar lipids and spermidine as the major polyamine. DNA-DNA hybridization results showed that strain $\mathrm{JZ}-2^{\top}$ had low genomic relatedness with $S$. cloacae JCM $10874^{\top}$ (34\%) and S. ummariense CCM $7431^{\top}$ (23\%). Based on the phenotypic, genotypic and phylogenetic data presented, strain $\mathrm{JZ}-2^{\top}$ is considered to represent a novel species of the genus Sphingobium, for which the name Sphingobium faniae sp. nov. is proposed. The type strain is JZ-2 ${ }^{\top}\left(=\right.$ CGMCC $1.7749^{\top}=$ DSM $\left.21829^{\top}\right)$.
\end{abstract}


In the present study, the taxonomic position of strain JZ-2 ${ }^{\mathrm{T}}$ was characterized by using a polyphasic approach.

For investigation of morphological features, strain JZ-2 ${ }^{\mathrm{T}}$ was cultivated aerobically on LB agar plates for 3 days at $30{ }^{\circ} \mathrm{C}$. Cell morphology was examined by light microscopy (BH-2; Olympus) and transmission electron microscopy (H-7650; Hitachi). For the latter, cells were stained with $2 \%$ potassium phosphotungstate. The Gram stain was performed according to the classical Gram procedure (Buck, 1982). Growth at 4,30 and $42{ }^{\circ} \mathrm{C}$ on LB agar was monitored for 10 days. Salt tolerance was determined by cultivating the organism in liquid $\mathrm{LB}$ supplemented with $\mathrm{NaCl}$ at final concentrations in the range $0-5.0 \%$. Oxidase and catalase tests were carried out as described by Ohta \& Hattori (1983). Urease production and citrate utilization were determined according to Cowan \& Steel (1965). Hydrolysis of starch, the methyl red test, indole production and the Voges-Proskauer reaction were determined as described by Smibert \& Krieg (1994). The phenotypic characteristics of the new isolate were determined by using the API 20NE system (bioMérieux) according to the manufacturer's instructions. Tests for biodegradation of several pyrethroids (fenpropathrin, deltamethrin, fenvalerate, cypermethrin, permethrin and cyhalothrin) were carried out according to the methods described by Maloney et al. (1988). Polar lipid, quinone and cellular fatty acid analyses of strain JZ- $2^{\mathrm{T}}$ were carried out by the Identification Service of the Deutsche Sammlung von Mikroorganismen und Zellkulturen (DSMZ, Braunschweig, Germany) as described by Tindall (1990a, b). Fatty acid profiles of strain JZ-2 ${ }^{\mathrm{T}}$ were obtained by using the Sherlock Microbial Identification System (Microbial ID, Inc.). For polyamine analysis, strain JZ- ${ }^{\mathrm{T}}$ was grown on PYE medium $(0.3 \%$ peptone from casein, $0.3 \%$ yeast extract, $\mathrm{pH} 7.2)$ and harvested at approximately $70 \%$ of the maximum optical density and, after lyophilization, polyamines were extracted and analysed by HPLC according to Busse \& Auling (1988) and Busse et al. (1997).

Genomic DNA from strain $\mathrm{JZ}-2^{\mathrm{T}}$ was extracted and purified according to standard procedures (Sambrook \& Russell, 2001). The purified PCR product was sequenced by using an automated sequencer (model 3730; Applied Biosystems). The 16S rRNA gene sequence was compared with known sequences found in the GenBank database by using the BLAST program of the National Center for Biotechnology Information (http://www.ncbi.nlm.nih.gov/ BLAST/). The alignment of the 16S rRNA gene sequences of strain $\mathrm{JZ}-2^{\mathrm{T}}$ and recognized species of the genus Sphingobium was compared by using CLUSTAL $\mathrm{x}$ software (Thompson et al., 1997), and phylogenetic analysis was performed with MEGA version 3.1 (Kumar et al., 2004). An evolutionary distance matrix was calculated by using Kimura's two-parameter distance model (Kimura, 1980), and a phylogenetic tree was reconstructed with the neighbour-joining method; the robustness of the tree was examined by bootstrap analysis of 1000 replications (Saitou \& Nei, 1987). The G $+\mathrm{C}$ content of the DNA of strain JZ$2^{\mathrm{T}}$ was determined by thermal denaturation (Mandel \&
Marmur, 1968), for which Escherichia coli K-12 was used as a standard. DNA-DNA hybridization experiments were performed fluorometrically according to the method of Ezaki et al. (1989).

The almost-complete 16S rRNA gene sequence (1401 nt) of strain $\mathrm{JZ}-2^{\mathrm{T}}$ was determined in this study. A tree depicting the phylogenetic affinity of this strain within the genus Sphingobium and other related taxa is shown in Fig. 1. Evaluation of the tree topology revealed that strain $\mathrm{JZ}-2^{\mathrm{T}}$ clustered with species of the genus Sphingobium and formed a subclade with Sphingobium cloacae JCM $10874^{\mathrm{T}}$ and Sphingobium ummariense RL- $3^{\mathrm{T}}$. Strain $\mathrm{JZ}-2^{\mathrm{T}}$ showed levels of 16S rRNA gene sequence similarity of 98.3 and $97.1 \%$ to S. cloacae JCM $10874^{\mathrm{T}}$ and S. ummariense RL-3 ${ }^{\mathrm{T}}$, respectively, and $94.8-96.9 \%$ to the type strains of other species of the genus Sphingobium. In order to clarify the taxonomic relationship of strain $\mathrm{JZ}-2^{\mathrm{T}}$ with $S$. cloacae JCM $10874^{\mathrm{T}}$ and S. ummariense RL-3 ${ }^{\mathrm{T}}$, DNA-DNA hybridization experiments were performed. Levels of DNA-DNA relatedness between strain JZ-2 ${ }^{\mathrm{T}}$ and S. cloacae JCM $10874^{\mathrm{T}}$ and S. ummariense RL- $3^{\mathrm{T}}$ were 34 and $23 \%$, respectively, well below the $70 \%$ cut-off point recommended for the delineation of bacterial species (Wayne et al., 1987).

Strain $\mathrm{JZ}-2^{\mathrm{T}}$ possessed chemical markers that supported its assignment to the genus Sphingobium. Cellular fatty acid analysis revealed the presence of $\mathrm{C}_{14: 0} 2-\mathrm{OH}(5.12 \%$ of the total) and $\mathrm{C}_{18: 1} \omega 7 c(57.34 \%)$ as the major hydroxylated and non-hydroxylated components, respectively. Other main fatty acids (exceeding $4 \%$ of the total) detected were $\mathrm{C}_{16: 0} \quad(13.76 \%), \quad 11$-methyl $\mathrm{C}_{18: 1} \omega 7 c \quad(4.96 \%)$ and $\mathrm{C}_{17: 1} \omega 6 c(4.77 \%)$. The detailed fatty acid profiles of strain $\mathrm{JZ}-2^{\mathrm{T}}$ and recognized Sphingobium species are shown in Supplementary Table S1. Polar lipid analysis showed that strain JZ-2 ${ }^{\mathrm{T}}$ contained diphosphatidylglycerol, phosphatidylglycerol, phosphatidylcholine, phosphatidylmonomethylethanolamine, phosphatidylethanolamine and two sphingoglycolipids (Supplementary Fig. S3). The major respiratory quinone was ubiquinone Q-10 (92\%); Q-9 $(8 \%)$ was also detected as a minor component. Strain JZ$2^{\mathrm{T}}$ contained spermidine as the predominant polyamine [25-36 $\mu \mathrm{mol}$ (g dry weight $\left.)^{-1}\right]$, with trace amounts of spermine $\left[0.14-0.19 \mu \mathrm{mol}(\mathrm{g} \text { dry weight })^{-1}\right]$. This polyamine pattern is in agreement with data for recognized species of the genus Sphingobium. The DNA G + C content of strain $\mathrm{JZ}-2^{\mathrm{T}}$ was $63.8 \pm 0.8 \mathrm{~mol} \%$ (mean $\pm \mathrm{SD}$ of 6 determinations), which fell within the range observed for other members of the genus Sphingobium (62-67 mol\%; Takeuchi et al., 2001).

Cells of strain JZ-2 ${ }^{\mathrm{T}}$ were strictly aerobic, Gram-negative, non-sporulating, rod-shaped $(0.5-0.6 \times 1.1-1.2 \mu \mathrm{m})$ and non-motile (Supplementary Fig. S4). Colonies on LB agar were circular, smooth with entire margins, semi-transparent and pale yellow and formed brown water-soluble pigment after 2 days incubation at $30{ }^{\circ} \mathrm{C}$. Strain JZ-2 ${ }^{\mathrm{T}}$ was able to tolerate up to $1.5 \% \mathrm{NaCl}$, whereas S. cloacae JCM $10874^{\mathrm{T}}$ was able to tolerate $3 \% \mathrm{NaCl}$. The novel strain 


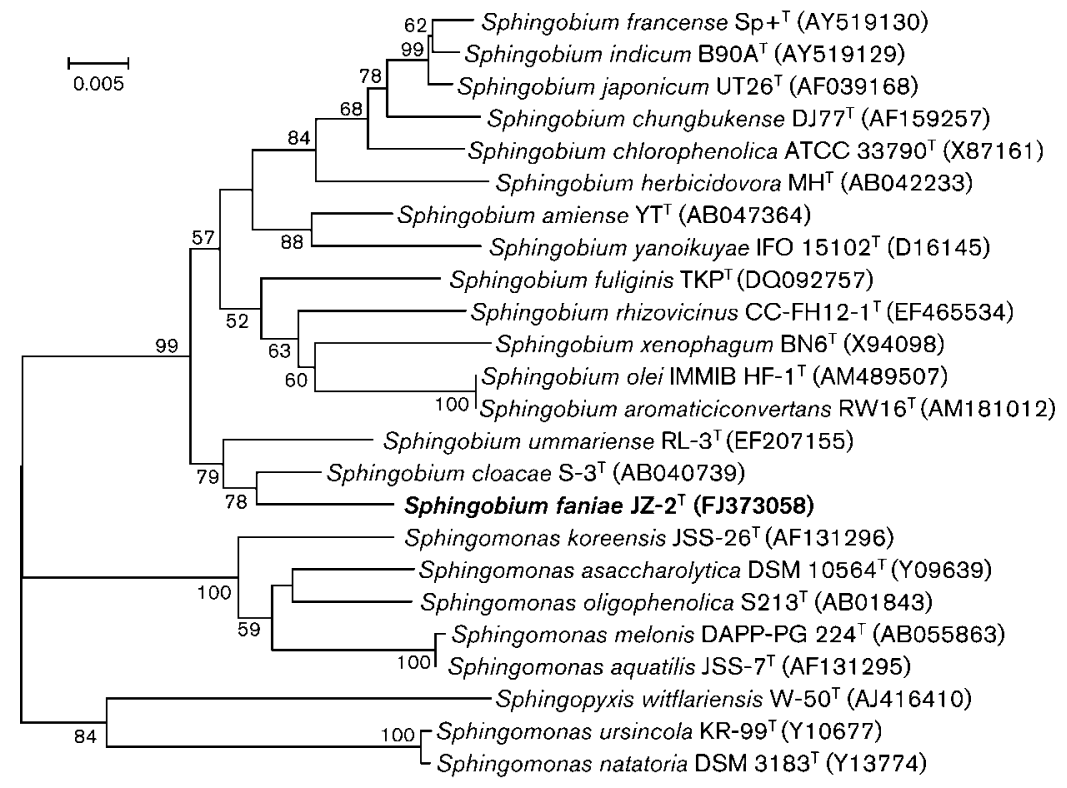

Fig. 1. Phylogenetic tree constructed by the neighbour-joining method based on 16S rRNA gene sequences of strain $\mathrm{JZ}-2^{\top}$ and the type strains of related species. Bootstrap values, expressed as percentages of 1000 replications, are given at branch points. Bar, 0.005 substitutions per nucleotide position. assimilated D-mannose and malate, characteristics which differentiated it from S. cloacae JCM $10874^{\mathrm{T}}$ and $S$. ummariense $\mathrm{RL}-3^{\mathrm{T}}$. Strain $\mathrm{JZ}-2^{\mathrm{T}}$ was capable of degrading efficiently various pyrethroids tested, such as fenpropathrin, deltamethrin, fenvalerate, cypermethrin, permethrin and cyhalothrin, whereas $S$. cloacae JCM $10874^{\mathrm{T}}$ and $S$. ummariense $\mathrm{RL}-3^{\mathrm{T}}$ could not. Differential phenotypic characteristics between strain $\mathrm{JZ}-2^{\mathrm{T}}$ and recognized species of the genus Sphingobium are given in Table 1. Based on this unique phenotypic profile, strain $\mathrm{JZ}-2^{\mathrm{T}}$ was clearly differentiated from recognized species of the genus Sphingobium.

On the basis of its phenotypic, genotypic and phylogenetic characteristics, strain $\mathrm{JZ}-2^{\mathrm{T}}$ is considered to represent a novel species of the genus Sphingobium, for which the name Sphingobium faniae sp. nov. is proposed.

Table 1. Differential phenotypic characteristics between strain $J Z-2^{\top}$ and recognized Sphingobium species

Strains: 1 , JZ-2 $2^{\mathrm{T}}$; 2, S. cloacae JCM $10874^{\mathrm{T}}$; 3, S. ummariense CCM $7431^{\mathrm{T}}$ (data in columns $1-3$ from the present study unless indicated otherwise); 4, S. chlorophenolicum DSM 8671 ${ }^{\mathrm{T}}$ (Ushiba et al., 2003); 5, S. japonicum UT26 ${ }^{\mathrm{T}}$ (Pal et al., 2005); 6, S. francense $\mathrm{Sp}+{ }^{\mathrm{T}}$ (Pal et al., 2005); 7, S. indicum B90A ${ }^{\mathrm{T}}$ (Pal et al., 2005); 8, S. amiense $\mathrm{YT}^{\mathrm{T}}$ (Ushiba et al., 2003); 9, S. herbicidovorans DSM $11019^{\mathrm{T}}$ (Ushiba et al., 2003); 10, S. fuliginis DSM $18781^{\mathrm{T}}$ (Prakash \& Lal, 2006); 11, S. xenophagum BN6 ${ }^{\mathrm{T}}$ (Stolz et al., 2000); 12, S. olei IMMIB HF-1 ${ }^{\mathrm{T}}$ (Young et al., 2007); 13, S. rhizovicinum CCFH12-1 ${ }^{\mathrm{T}}$ (Young et al., 2008); 14, S. yanoikuyae JCM 7371 ${ }^{\mathrm{T}}$ (Ushiba et al., 2003); 15, S. chungbukense KCTC 2955 ${ }^{\mathrm{T}}$ (Kim et al., 2000); 16, S. aromaticiconvertens DSM $12677^{\mathrm{T}}$ (Wittich et al., 2007). ND, No data available.

\begin{tabular}{|c|c|c|c|c|c|c|c|c|c|c|c|c|c|c|c|c|}
\hline Characteristic & 1 & 2 & 3 & 4 & 5 & 6 & 7 & 8 & 9 & 10 & 11 & 12 & 13 & 14 & 15 & 16 \\
\hline Motility & - & $-a_{*}$ & $-{ }^{b}$ & - & - & - & - & ND & + & - & ND & $\mathrm{ND}$ & + & + & + & - \\
\hline \multicolumn{17}{|l|}{ Assimilation of: } \\
\hline D-Glucose & + & - & + & + & + & + & + & + & + & + & + & + & + & + & + & - \\
\hline L-Arabinose & + & - & + & - & + & + & + & - & + & + & + & + & + & + & + & - \\
\hline D-Mannose & + & - & - & - & - & - & - & - & - & ND & - & - & + & - & + & - \\
\hline Malate & + & - & - & - & ND & ND & ND & - & + & ND & + & + & + & + & - & - \\
\hline Maltose & - & - & + & - & ND & ND & ND & + & + & + & + & + & + & + & + & - \\
\hline Citrate & - & - & - & - & - & - & $\mathrm{ND}$ & - & - & $\mathrm{ND}$ & + & - & + & + & - & - \\
\hline Aesculin hydrolysis & - & - & + & + & + & + & - & - & + & - & - & + & + & + & + & - \\
\hline \multicolumn{17}{|l|}{ Activity of: } \\
\hline Catalase & + & + & - & + & + & + & + & + & + & + & + & - & - & + & + & + \\
\hline Urease & + & + & - & + & ND & ND & + & - & - & - & - & - & - & + & ND & $\mathrm{ND}$ \\
\hline$\beta$-Galactosidase & + & - & + & - & $\mathrm{ND}$ & $\mathrm{ND}$ & ND & - & - & - & - & - & + & + & - & + \\
\hline Nitrate reductase & - & - & - & - & ND & $\mathrm{ND}$ & ND & - & - & + & - & - & + & - & ND & - \\
\hline
\end{tabular}

${ }^{\star}$ Data from: $a$, Ushiba et al. (2003); $b$, Singh \& Lal (2009). 


\section{Description of Sphingobium faniae sp. nov.}

Sphingobium faniae (fan'i.ae. N.L. fem. n. faniae of Fan, to honour Yun-Liu Fan, a respected molecular biologist, for her contributions to the development of agricultural genetic engineering in China).

Cells are Gram-negative, aerobic, non-sporulating, rodshaped $(0.5-0.6 \times 1.1-1.2 \mu \mathrm{m})$ and non-motile. Colonies on LB agar are circular, smooth, entire, semi-transparent and pale yellow and form brown, water-soluble pigment after 2 days incubation at $30{ }^{\circ} \mathrm{C}$. Optimum growth at $30{ }^{\circ} \mathrm{C}$ and $\mathrm{pH}$ 7.5; growth is not observed at 4 or $42{ }^{\circ} \mathrm{C}$. Able to tolerate $1.5 \% \mathrm{NaCl}$. Positive for oxidase, urease and catalase, but negative for hydrolysis of gelatin and starch, citrate utilization, the methyl red test, indole production and the Voges-Proskauer reaction. The major non-polar fatty acid is $\mathrm{C}_{18: 1} \omega 7 c$ and the major 2-hydroxy fatty acid is $\mathrm{C}_{14: 0}$ 2-OH. Polar lipids are diphosphatidylglycerol, phosphatidylmonomethylethanolamine, phosphatidylcholine, phosphatidylglycerol, phosphatidylethanolamine and two sphingoglycolipids. The major cellular polyamine is spermidine, and the major quinone is ubiquinone Q-10. The DNA $\mathrm{G}+\mathrm{C}$ content of the type strain is $63.8 \pm 0.8 \mathrm{~mol} \%$. Positive for urease, $\beta$-galactosidase, hydrolysis of arginine and assimilation of glucose, arabinose, mannose, mannitol, potassium gluconate, capric acid and malic acid; negative for nitrate reduction, hydrolysis of gelatin and aesculin, glucose fermentation and assimilation of L-tryptophan, maltose, phenylacetic acid, adipic acid, $\mathrm{N}$-acetylglucosamine and trisodium citrate. Sensitive to penicillin $(30 \mu \mathrm{g})$, tetracycline $(10 \mu \mathrm{g})$, gentamicin $(15 \mu \mathrm{g})$, erythromycin $(10 \mu \mathrm{g})$, chloramphenicol $(30 \mu \mathrm{g})$; resistant to ampicillin $(50 \mu \mathrm{g})$ and streptomycin $(50 \mu \mathrm{g})$.

The type strain, JZ-2 ${ }^{\mathrm{T}} \quad\left(=\mathrm{CGMCC} \quad 1.7749^{\mathrm{T}}=\mathrm{DSM}\right.$ $21829^{\mathrm{T}}$ ), was isolated from activated sludge of an aerobic, pyrethroid-contaminated wastewater of the Yangnong Chemical Group Co., Ltd (Jiangsu, China).

\section{Acknowledgements}

We are grateful to Dr Susanne Verbarg and Dr B. J. Tindall (DSMZ) for analysis of polar lipids, quinones and cellular fatty acids. We would also like to thank Dr Bing-jun Yu (College of Life and Science, Nanjing Agricultural University) for analysis of polyamines. This work was supported by the National High Technology Research and Development Program of China (2006AA10Z402), the Natural Science Foundation of Jiangsu Province, China (BK2008331), and the Chinese National Technology Platform Programs (2005DKA21201-2).

\section{References}

Bradbury, S. P. \& Coats, J. R. (1989). Toxicokinetics and toxicodynamics of pyrethroid insecticides in fish. Environ Toxicol Chem 8, 373-380.

Buck, J. D. (1982). Nonstaining (KOH) method for determination of gram reactions of marine bacteria. Appl Environ Microbiol 44, 992-993.
Busse, H.-J. \& Auling, G. (1988). Polyamine pattern as a chemotaxonomic marker within the Proteobacteria. Syst Appl Microbiol 11, 1-8.

Busse, H. J., Bunka, S., Hensel, A. \& Lubitz, W. (1997). Discrimination of members of the family Pasteurellaceae based on polyamine patterns. Int J Syst Bacteriol 47, 698-708.

Cowan, S. T. \& Steel, K. J. (1965). Manual for the Identification of Medical Bacteria. London: Cambridge University Press.

Ezaki, T., Hashimoto, Y. \& Yabuuchi, E. (1989). Fluorometric deoxyribonucleic acid-deoxyribonucleic acid hybridization in microdilution wells as an alternative to membrane filter hybridization in which radioisotopes are used to determine genetic relatedness among bacterial strains. Int J Syst Bacteriol 39, 224-229.

Grant, R. J., Daniell, T. J. \& Betts, W. B. (2002). Isolation and identification of synthetic pyrethroid-degrading bacteria. J Appl Microbiol 92, 534-540.

Katsuda, Y. (1999). Development of and future prospects for pyrethroid chemistry. Pestic Sci 55, 775-782.

Kidd, H. \& James, D. R. (editors) (1991). The Agrochemicals Handbook, 3rd edn, pp. 2-13. Cambridge: Royal Society of Chemistry Information Services.

Kim, S.-J., Chun, J., Bae, K. S. \& Kim, Y.-C. (2000). Polyphasic assignment of an aromatic-degrading Pseudomonas sp., strain DJ77, in the genus Sphingomonas as Sphingomonas chungbukensis sp. nov. Int J Syst Evol Microbiol 50, 1641-1647.

Kimura, M. (1980). A simple method for estimating evolutionary rates of base substitutions through comparative studies of nucleotide sequences. J Mol Evol 16, 111-120.

Kumar, S., Tamura, K. \& Nei, M. (2004). MEGA3: integrated software for molecular evolutionary genetics analysis and sequence alignment. Brief Bioinform 5, 150-163.

Kumar, A., Sharma, B. \& Pandey, R. S. (2008). Cypermethrin and $\lambda$ cyhalothrin induced alterations in nucleic acids and protein contents in a freshwater fish, Channa punctatus. Fish Physiol Biochem 34, 331338.

Lee, S., Gan, J., Kim, J. S., Kabashima, J. N. \& Crowley, D. E. (2004). Microbial transformation of pyrethroid insecticides in aqueous and sediment phases. Environ Toxicol Chem 23, 1-6.

Maloney, S. E., Maule, A. \& Smith, A. R. W. (1988). Microbial transformation of the pyrethroid insecticides: permethrin, deltamethrin, fastac, fenvalerate, and fluvalinate. Appl Environ Microbiol 54, 2874-2876.

Mandel, M. \& Marmur, J. (1968). Use of ultraviolet absorbancetemperature profile for determining the guanine plus cytosine content of DNA. Methods Enzymol 12B, 195-206.

Ohta, H. \& Hattori, T. (1983). Agromonas oligotrophica gen. nov., sp. nov., a nitrogen-fixing oligotrophic bacterium. Antonie van Leeuwenhoek 49, 429-446.

Pal, R., Bala, S., Dadhwal, M., Kumar, M., Dhingra, G., Prakash, O., Prabagaran, S. R., Shivaji, S., Cullum, J. \& other authors (2005). Hexachlorocyclohexane-degrading bacterial strains Sphingomonas paucimobilis B90A, UT26 and Sp+, having similar lin genes, represent three distinct species, Sphingobium indicum sp. nov., Sphingobium japonicum sp. nov. and Sphingobium francense sp. nov., and reclassification of [Sphingomonas] chungbukensis as Sphingobium chungbukense comb. nov. Int J Syst Evol Microbiol 55, 1965-1972.

Prakash, O. \& Lal, R. (2006). Description of Sphingobium fuliginis sp. nov., a phenanthrene-degrading bacterium from a fly ash dumping site, and reclassification of Sphingomonas cloacae as Sphingobium cloacae comb. nov. Int J Syst Evol Microbiol 56, 2147-2152. 
Saitou, N. \& Nei, M. (1987). The neighbor-joining method: a new method for reconstructing phylogenetic trees. Mol Biol Evol 4, 406-425.

Sakata, S., Mikami, N. \& Yamada, H. (1992). Degradation of pyrethroid optical isomers by soil microorganisms. J Pestic Sci 17, 181-189.

Sambrook, J. \& Russell, D. W. (2001). Molecular Cloning: a Laboratory Manual, 3rd edn. Cold Spring Harbor, NY: Cold Spring Harbor Laboratory.

Singh, A. \& Lal, R. (2009). Sphingobium ummariense sp. nov., a hexachlorocyclohexane $(\mathrm{HCH})$-degrading bacterium, isolated from HCH-contaminated soil. Int J Syst Evol Microbiol 59, 162-166.

Smibert, R. M. \& Krieg, N. R. (1994). Phenotypic characterization. In Methods for General and Molecular Bacteriology, pp. 607-654. Edited by P. Gerhardt, R. G. E. Murray, W. A. Wood \& N. R. Krieg. Washington, DC: American Society for Microbiology.

Stolz, A., Schmidt-Maag, C., Denner, E. B., Busse, H. J., Egli, T. \& Kämpfer, P. (2000). Description of Sphingomonas xenophaga sp. nov. for strains $\mathrm{BN}^{\mathrm{T}}$ and $\mathrm{N}, \mathrm{N}$ which degrade xenobiotic aromatic compounds. Int J Syst Evol Microbiol 50, 35-41.

Takeuchi, M., Hamana, K. \& Hiraishi, A. (2001). Proposal of the genus Sphingomonas sensu stricto and three new genera, Sphingobium, Novosphingobium and Sphingopyxis, on the basis of phylogenetic and chemotaxonomic analyses. Int J Syst Evol Microbiol 51, 1405-1417.

Tallur, P. N., Megadi, V. B. \& Ninnekar, H. Z. (2008). Biodegradation of cypermethrin by Micrococcus sp. strain CPN 1. Biodegradation 19, $77-82$.

Thompson, J. D., Gibson, T. J., Plewniak, F., Jeanmougin, F. \& Higgins, D. G. (1997). The CLUSTAL_X windows interface: flexible strategies for multiple sequence alignment aided by quality analysis tools. Nucleic Acids Res 25, 4876-4882.

Tindall, B. J. (1990a). Lipid composition of Halobacterium lacusprofundi. FEMS Microbiol Lett 66, 199-202.
Tindall, B. J. (1990b). A comparative study of the lipid composition of Halobacterium saccharovorum from various sources. Syst Appl Microbiol 13, 128-130.

Tripathi, P. K. \& Singh, A. (2004). Toxic effects of cypermethrin and alphamethrin on reproduction and oxidative metabolism of the freshwater snail, Lymnaea acuminata. Ecotoxicol Environ Saf 58, 227235.

Ushiba, Y., Takahara, Y. \& Ohta, H. (2003). Sphingobium amiense sp. nov., a novel nonylphenol-degrading bacterium isolated from a river sediment. Int J Syst Evol Microbiol 53, 2045-2048.

Wayne, L. G., Brenner, D. J., Colwell, R. R., Grimont, P. A. D., Kandler, O., Krichevsky, M. I., Moore, L. H., Moore, W. E. C., Murray, R. G. E. \& other authors (1987). International Committee on Systematic Bacteriology. Report of the ad hoc committee on reconciliation of approaches to bacterial systematics. Int J Syst Bacteriol 37, 463-464.

Wittich, R. M. (1998). Degradation of dioxin-like compounds by microorganisms. Appl Microbiol Biotechnol 49, 489-499.

Wittich, R.-M., Busse, H.-J., Kämpfer, P., Tiirola, M., Wieser, M., Macedo, A. J. \& Abraham, W. R. (2007). Sphingobium aromaticiconvertens sp. nov., a xenobiotic-compound-degrading bacterium from polluted river sediment. Int J Syst Evol Microbiol 57, 306-310.

Young, C. C., Ho, M. J., Arun, A. B., Chen, W.-M., Lai, W.-A., Shen, F.-T., Rekha, P. D. \& Yassin, A. F. (2007). Sphingobium olei sp. nov., isolated from oil-contaminated soil. Int J Syst Evol Microbiol 57, 26132617.

Young, C. C., Arun, A. B., Kämpfer, P., Busse, H.-J., Lai, W.-A., Chen, W.-M., Shen, F.-T. \& Rekha, P. D. (2008). Sphingobium rhizovicinum sp. nov., isolated from rhizosphere soil of Fortunella hindsii (Champ. ex Benth.) Swingle. Int J Syst Evol Microbiol 58, 1801-1806.

Yu, Y. \& Fan, D. (2003). Preliminary study of an enzyme extracted from Alcaligenes sp. strain YF11 capable of degrading pesticides. Bull Environ Contam Toxicol 70, 367-371. 